Fixed Point Theory, 18(2017), No. 2, 493-502

DOI 10.24193/fpt-ro.2017.2.39

http://www.math.ubbcluj.ro/ nodeacj/sfptcj.html

\title{
FIXED POINT THEOREMS FOR COMPACT POTENTIAL OPERATORS IN HILBERT SPACES
}

\author{
A. BOUCENNA*, S. DJEBALI ${ }^{*, * * 1}$ AND T. MOUSSAOUI*** \\ *Laboratory of Fixed Point Theory and Applications \\ École Normale Supérieure, BP 92 \\ Kouba, 16006, Algiers, Algeria \\ E-mail: boucenna-amina@hotmail.fr \\ ** Department of Mathematics, Faculty of Sciences \\ Al Imam Mohammad Ibn Saud Islamic University (IMSIU) \\ P.O. Box 90950, Riyadh 11623, Saudi Arabia \\ E-mail: djebali@hotmail.com \\ *** Laboratory of Fixed Point Theory and Applications \\ École Normale Supérieure, BP 92 \\ Kouba, 16006, Algiers, Algeria \\ E-mail: moussaoui@ens-kouba.dz
}

\begin{abstract}
The aim of this paper is to present new fixed point theorems for compact potential operators in Hilbert spaces. A variational approach is used and applications to boundary value problems illustrate the existence results.

Key Words and Phrases: Potential operator, critical points, fixed point theorem, boundary value problem.
\end{abstract}

2010 Mathematics Subject Classification: 34B15, 47G40, 47H10, 58E30.

\section{REFERENCES}

[1] H. Amann, A note on degree theory for gradient mappings, Proc. Amer. Math. Soc., 85(1982), no. $4,591-595$.

[2] A. Avez, Calcul Différentiel, Masson, 1983.

[3] H. Brezis, Analyse Fonctionnelle, Théorie et Applications, Masson, Paris, 1983.

[4] J. Chabrowski, Variational Methods for Potential Operator Equations, Mathematisch Centrum, Amsterdam, 1979.

[5] Y. Cui, J. Sun, Fixed point theorems for a class of nonlinear operators in Hilbert spaces and applications, Positivity, 15(2011), 455-464.

\footnotetext{
${ }^{1}$ Corresponding author.
} 
[6] E.W.C. van Groesen, Variational Methods for Nonlinear Operator Equations, In Nonlinear Analysis: Proceedings of the Lectures of a Colloquium on Nonlinear Analysis. Mathematisch Centrum, Amsterdam, (1976), 100-191.

[7] O. Kavian, Introduction à la Théorie des Points Critiques et Applications aux Problèmes Elliptiques, Springer-Verlag, 1993.

[8] A.A. Kilbas, H.M. Srivastava, J.J. Trujillo, Theory and Applications of Fractional Differential Equations, Elsevier Science, Amsterdam, 2006.

[9] P.H. Rabinowitz, A note on topological degree for potential operators, J. Math. Anal. Appl., 51(1975) 483-492.

Received: July 25, 2014; Accepted: February 26, 2016. 